\title{
Movimento dos Agricultores Sem Terra: uma luta nas páginas do “Correio do Povo" (1960-1964)
}

\author{
Movimiento de los Agricultores Sin Tierra: una lucha en las páginas del \\ "Correio do Povo"(1960-1964)
}

Landless Farmers Movement: A Struggle in the Pages of the "Correio do

Povo" (1960-1964)

\author{
Gabriela Brum Rosselli ${ }^{1}$ \\ Bárbara De La Rosa Elia ${ }^{2}$
}

\begin{abstract}
Resumo
O seguinte trabalho trata de uma pesquisa que faz parte de um projeto mais amplo intitulado "Mobilizações e movimentos sociais agrários, repressão e resistência do pré-1964 à ditadura civil-militar: as trajetórias do Master no Rio Grande do Sul e das Ligas Camponesas em Pernambuco", financiado pela CAPES no âmbito do edital "Memórias Brasileiras - Conflitos Sociais". Este projeto busca investigar mobilizações, reivindicações e movimentos sociais agrários, surgidos antes de 1964, bem como atos de repressão e violações de direitos contra camponeses e militantes ou lideranças de movimentos de luta pela terra. Em suma, a presente pesquisa, que se encontra em fase inicial, enfoca no Movimento dos Agricultores Sem Terra do RS (Master) visando aprofundar o estudo sobre suas origens, mobilizações e lutas, resgatando a memória e identidade de camponeses que foram protagonistas de tais lutas. O Master, no início da década de 1960, foi eloquente no conflito pela terra no RS, e através da imprensa da época, mais especificamente o jornal Correio do Povo, nos dedicamos à análise da abordagem acerca do movimento e dos conflitos no campo neste período, buscando averiguar como os conflitos aparecem (ou não); como o movimento e seus membros são caracterizados; como a questão da luta pela terra e a reforma agrária são veiculados no jornal e se ganha centralidade; entre outros tópicos abordados pelo periódico.
\end{abstract}

Palavras-Chave: Conflito por Terras; Jornal Correio do Povo; Movimento dos Agricultores Sem Terra; Movimento Social.

\section{Resumen}

El siguiente trabajo trata de una investigación que forma parte de un proyecto más amplio titulado "Movilizaciones y movimientos sociales agrarios, represión y resistencia del pre-1964 a la dictadura civilmilitar: las trayectorias del Master en Rio Grande do Sul y de las Ligas Campesinas en Pernambuco ", financiado por la CAPES en el marco del edicto" Memorias Brasileñas - Conflictos Sociales". Este proyecto busca investigar movilizaciones, reivindicaciones y movimientos sociales agrarios, surgidos antes de 1964, así como actos de represión y violaciones de derechos contra campesinos y militantes o liderazgos de movimientos de lucha por la tierra. En resumen, la presente investigación, que se encuentra en fase inicial, se enfoca en el Movimiento de los Agricultores Sin Tierra del RS (Master) para profundizar el estudio sobre sus orígenes, movilizaciones y luchas, rescatando la memoria e identidad de campesinos que fueron protagonistas de tales. luchas. El Master, a principios de la década de 1960, fue elocuente en el conflicto por la tierra en el RS, ya través de la prensa de la época, más específicamente el periódico Correo del Pueblo, nos dedicamos al análisis del abordaje acerca del movimiento y de los conflictos en el campo en este período , buscando averiguar cómo

\footnotetext{
1 Mestranda em História; Universidade Federal de Pelotas; Pelotas; Rio Grande do Sul; Brasil; gabeufpel@gmail.com. Trabalho apresentado no III Encontro Humanístico Multidisciplinar e II Congresso Latino-Americano em Estudos Humanísticos Multidisciplinares, Jaguarão/RS, Brasil, 2017.

2 Graduanda em História; Universidade Federal de Pelotas; Pelotas; Rio Grande do Sul; Brasil; barbaradelarosaelia@gmail.com.
} 
los conflictos aparecen (o no); como el movimiento y sus miembros se caracterizan; como la cuestión de la lucha por la tierra y la reforma agraria se transmiten en el periódico y se gana centralidad; entre otros temas abordados por el periódico.

Palabras claves: Conflicto por Tierras; Correio do Povo; Movimiento de los Agricultores Sin Tierra; Movimiento Social.

\begin{abstract}
The following work deals with a research that is part of a larger project entitled "Mobilizations and social movements agrarian, repression and resistance of the pre-1964 to the civil-military dictatorship: the trajectories of the Master in Rio Grande do Sul and the Peasant Leagues in Pernambuco ", funded by CAPES under the" Memórias Brasileiras - Social Conflicts "edict. This project seeks to investigate mobilizations, claims and agrarian social movements, which arose before 1964, as well as acts of repression and violations of rights against peasants and militants or leaders of movements for fighting for land. In short, this research, which is in the initial phase, focuses on the Landless Farmers Movement of RS (Master) aiming to deepen the study of their origins, mobilizations and struggles, rescuing the memory and identity of peasants who were protagonists of such fights The Master in the early 1960s was eloquent in the land conflict in RS, and through the press of the time, more specifically the Correio do Povo newspaper, we dedicated ourselves to analyzing the approach to movement and conflicts in the countryside in this period, trying to find out how the conflicts appear (or not); how the movement and its members are characterized; as the question of the struggle for land and agrarian reform are conveyed in the newspaper and centrality is gained; among other topics covered by the journal.
\end{abstract}

Keywords: Conflict by Land; newspaper Correio do Povo; Landless Farmers Movement; Social movement

\title{
1. Introdução
}

O Movimento dos Agricultores Sem Terra (Master) foi fundado em 1960 enquanto acontecia uma tentativa de retomada de uma área de 1.800 hectares no interior do município de Encruzilhada do Sul que há 50 anos estava em poder de 300 famílias de posseiros (ECKERT, 1984, p.67). Essa mobilização ocasionou a fundação da primeira associação de agricultores, cujos princípios se expandiram até dar origem a um movimento estadual mais estruturado, o Master apresentou-se, junto a outros movimentos referentes à luta de classes no campo, rumo à subversão da estrutura excludente que oprimia o campesinato. $\mathrm{O}$ movimento foi se institucionalizando e ganhando espaço, criando associações, mobilizações e ocupações de terras em várias regiões do RS. Sendo este movimento inserido no contexto histórico em que diversas reformas de base estiveram em pauta como ideias mobilizadoras de diferentes setores, ele defrontou em sua cerne, reforma agrária, com os maiores impasses em voga.

Sendo assim, este estudo objetiva pesquisar motivações e atuações do Master, entendendo que a principal pauta deste movimento sempre foi o atendimento de reivindicações sociais, e que visou a legalidade como ferramenta amparadora. Desta forma o presente trabalho debruça-se em análises de recortes de jornais e busca agregar novas fontes e acervos, sistematizando informações e aprofundando as análises e buscando perceber como o Master e outros movimentos de luta pela terra foram reprimidos, assim como dando seguimento aos trabalhos iniciados pela Comissão Camponesa da Verdade. Dedica-se em 
singular, sobre as discussões relativas ao movimento e temas agrários projetadas no jornal Correio do Povo, entre os anos de 1960 e 1964, sendo extensamente publicadas em textos de opiniões e informações de acontecimentos.

De acordo com constatações realizadas pela Comissão Camponesa da Verdade, pesquisas e produções acadêmicas sobre o protagonismo de camponeses na luta contra a ditadura e também nos processos de reparação ainda são negligenciados. Essa invisibilização dos camponeses enquanto sujeitos políticos acorre como um mecanismo político de não identificar e, consequentemente "não justiça", sendo essencial o desenvolvimento de trabalhos de pesquisa, visando reconstruir a memória e identidade, "único caminho para, além de resgatar a história e materializar reconhecimentos, viabilizar possíveis formas de reparação" (SAUER e SARAIVA, 2015, p.32).

Sob os preâmbulos nacional-desenvolvimentista, a reforma agrária eclodiu de maneira significativa no período que antecede ao Golpe civil-militar, como pauta para que o capitalismo industrial no Brasil pudesse atingir nível superior de desenvolvimento. (NAVARRO, 2004). Ainda segundo o autor:

\footnotetext{
De um lado, era preciso aumentar a produção agrícola (alimentos, matérias-primas para a indústria etc.) ao mesmo tempo em que se buscava ampliar o mercado interno para os bens manufaturados. De outro lado, prevendo situações crescentes de tensões e conflitos sociais, propunha-se uma melhor distribuição de terras improdutivas. Num depoimento, Darcy Ribeiro, um dos mais íntimos assessores de Goulart, sintetizou a visão do governo sobre o assunto: "Jango, latifundiário, queria fazer a reforma agrária para defender a propriedade e assegurar a fartura, evitando o desespero popular e a convulsão social" (NAVARRO, 2004, p. 22)
}

No caso do Rio Grande do Sul, popularmente conhecido como um estado brasileiro de alta dependência econômica para com o setor agropecuário, a conjuntura estadual que já vinha convergindo para o aumento da concentração de terras, evidenciando a questão agrária como um dos eixos centrais de dominação e acumulação de riquezas do país, acaba por demonstrar suas contradições, com a consequência do fortalecimento de movimentos agrários reivindicatórios. Deve-se ainda apontar que as reivindicações por terras combinada com clamores por direitos, muitas vezes há muito já conquistado no meio urbano, acirraram ao longo do tempo a dicotomia de interesses entre o Master e o também movimento político organizado dos ruralistas gaúchos.

Outro fato marcante para referenciar o tratamento advindo de grandes nomes e instituições, desta vez já em 1963, para com a questão da reforma agrária, foi a proposta de emenda 
constitucional apresentada por João Goulart, que previa a desapropriação de terras em troca de títulos da dívida pública.

Caiam sem apelação todos os projetos parlamentares com vistas à derrogação do dispositivo constitucional que impunha o pagamento prévio e em dinheiro pelas desapropriações de terras, como se deu com os projetos dos deputados José Joffily, em 1961, e do deputado Bocaiuva Cunha, em 1963. Mesmo o limitadíssimo projeto reformista elaborado por uma comissão do Congresso, sob a presidência do senador udenista Milton Campos, encontrou o bloqueio da própria UDN." (GORENDER,1998, p. 58)

Cenário este, portanto, de tensões permanentes que não poderia passar despercebidas pelos veículos de informação da época. No que diz respeito ao Correio do Povo, nota-se crescente interesse em pautar a Reforma agrária em suas colunas. Contudo o formato, e até mesmo pequenas mudanças de tendências ideológicas ou abordagem, transfiguraram-se no passar dos anos aqui estudados.

\section{A pesquisa em jornais}

Referente à análise de recortes de jornais, haja vista sua importância ao passo que ao longo de dois séculos, documentos escritos oficiais foram a única fonte considerada válida na elaboração de trabalhos científicos. Eles tinham o significado de prova e sua apropriação pelos historiadores se reduzia a simples cópia. Desta forma, a produção historiográfica, utilizando dessa tipologia documental, resultava em uma escrita da história factual e centrada nos grandes personagens, típica do século XIX. Consequentemente, o viés político predominava nos textos historiográficos identificados como positivistas.

Dado que a concepção de história foi se expandindo, uma nova corrente, denominada marxista, modificou o antigo enfoque mudando seu viés, do campo da política, para a infraestrutura, base sobre a qual se erguiam as demais instâncias. Em um movimento relativo, as pesquisas passaram a privilegiar as fontes ainda escritas, porém de natureza econômica, com destaque nos dados estatísticos e quantitativos. Outras fontes eram ainda utilizadas com menor recorrência. Seria por meio do primeiro corpus documental que se alcançaria projetar e analisar a sociedade mais ampliada, percebida em suas múltiplas especificidades. (LUCA, 2006, p.26).

Foi a Escola dos Annales que possibilitou perspectivas para novas abordagens onde as análises macro acabaram por indicar para espaços multifacetados nos quais cada instância do social suscitava questões e reflexões cada vez mais pontuais, até então negligenciadas. O desenvolvimento desta corrente historiográfica em suas fases posteriores levou ao início de 
estudos e lograram notável atenção. Nesta nova perspectiva, os documentos escritos oficiais não eram mais suficientes e novas fontes deveriam entrar em cena: mídias, textos literários, fotografias, correspondências, memórias escritas e orais, etc. (BURKE, 2004, p.15).

O objetivo seria manifestar, usando como apoio estes novos aportes documentais, as complexas relações sociais e o meio cultural em que os personagens históricos estavam inseridos. A concepção de sujeito histórico não se compreendia somente aos grandes homens, incluía agora sujeitos das mais diversas classes sociais.

Tomando como exemplo a pesquisa sobre o Movimento dos Agricultores Sem Terra em determinado período, podemos constatar que, não bastam consultas aos documentos gerados e produzidos por órgãos públicos - como relatórios, regulamentos, atos normativos, etc. Eles, sem dúvida elucidam nuances importantes do processo de elaboração do movimento, porém são impotentes para desvendar textos de opinião e o impacto que gerou na população e até mesmo as omissões de tal por alguns e, tampouco, nos oferecem fundamentos para conhecer mais profundamente o universo social e cultural. A partir desses hiatos evidenciados pela documentação oficial consideramos essencial a realização de análise documental de fontes primárias, que são recortes de jornais do periódico Correio do Povo, além de levantamentos bibliográficos sobre o objeto de pesquisa. Ao analisar os jornais, atentamos a alguns cuidados metodológicos para o uso e este tipo de fonte. Salvaguardar, e organizar a documentação são ações necessárias para a preservação da memória. Kellner nos ajuda a compreender melhor a capacidade e complexidade das mídias enquanto objeto de pesquisa, "os meios dominantes de informação e entretenimento são uma fonte profunda de informação e muitas vezes não percebidas de pedagogia cultural” (KELLNER, 2001, p.95). Segundo Kellner, as mídias ajudam a formar e modelar visões e valores de mundo. A partir desses pressupostos, podemos compreender um pouco melhor o impacto das mídias na cultura e a importância de se levantar a discussão envolvendo a pesquisa.

Já Tania Regina de Luca, acrescenta que "sempre será difícil sabermos que influências ocultas exerciam-se num momento dado sobre um órgão de informação, qual o papel desempenhado, por exemplo, pela distribuição da publicidade.” (LUCA, 2006, p.116). Claúdio Elmir (1995) atenta para algumas armadilhas que o historiador enfrenta ao pesquisar em jornais. É importante levar em consideração que "um jornal jamais pode ser visto como um dado", a leitura que o historiador deve fazer é diferenciada da feita pela população no geral. A leitura deve ser realizada com meticulosidade e "deve ser demorada, deve ser exaustiva." (ELMIR, 1995, p.21). Desta forma, a triagem feita pelo jornal com relação ao movimento de agricultores sem terras deve ser vista de maneira cuidadosa, visto que, tal 
posicionamento pode interferir para o negligenciamento do protagonismo dos agricultores, ficando estes no esquecimento. As reflexões de Maria Helena Capelato se tornam relevantes, ao indicarem que:

a reconstituição das lutas políticas e sociais através da imprensa tem sido o alvo de muitas das pesquisas recentes. Nos vários tipos de periódicos e até mesmo em cada um deles encontramos projetos políticos e visões de mundo representativos de vários setores da sociedade. (CAPELATO, 1988, p.34).

Desta forma, um dos benefícios da leitura dos discursos expressos nos periódicos é que possibilitam acompanhar o movimento das ideias que circulam no período pesquisado, Maria Capelato também destaca que:

o confronto das falas, que exprimem ideias e práticas, permite ao pesquisador captar, com riqueza de detalhes, o significado da atuação de diferentes grupos que se orientam por interesses específicos.[...] Os jornais oferecem vasto material para o estudo da vida cotidiana. Os costumes e práticas sociais, o folclore, enfim, todos os aspectos do dia-a-dia estão registrados em suas páginas. (CAPELATO, 1988, p.34).

Outra discussão relevante para a realização deste trabalho é o debate sobre memória e identidade, visto que se busca conhecer os nomes, as trajetórias e bandeiras destes camponeses, bem como analisar elementos sobre sua identidade enquanto movimento social. Haja vista a necessidade de se pensar e discutir a memória desses camponeses Joël Candau colabora:

\footnotetext{
Hoje, numerosas memórias são destruídas ou elas próprias desaparecem. É o caso daquelas que denominei como grandes memórias organizadoras. Mas, ao mesmo tempo, outras memórias nascem menos expansivas, mais particulares, mas frequentemente abundantes e robustas, seja no movimento associativo, no esporte [...] a política, o mundo do espetáculo e tantos outros domínios. Essas memórias são os fundamentos de identidades em recomposição, que na maior parte do tempo hesitam entre as tentações hegemônicas e o consentimento a um tipo de relativismo memorial. (CANDAU, 2014, p.193).
}

\section{3, O Master no Correio do Povo}

A etapa do projeto que diz respeito às pesquisas sobre o Master está em processo inicial, no entanto já é possível perceber algumas considerações importantes a partir da sistematização do material para a criação de um banco de dados referentes às notícias veiculadas pelo jornal Correio do Povo. O periódico fundado em Porto Alegre em 1895 por Francisco Antônio Vieira Caldas Júnior foi destacado como órgão independente de vinculações partidárias. Em 1935, quando a direção do jornal passou a Breno Caldas, filho de 
Caldas Júnior, este se dizia conservar o jornal na linha de neutralidade, entretanto é possível observar a indisposição do jornal contra o governador Leonel de Moura Brizola - que obtinha forte vinculação com o MASTER - e João Goulart, além de ter "contribuído para a eclosão do movimento militar de 1964" (DILLENBURG, 1997, p.6). Ainda de acordo com o autor:

Segundo Breno Caldas, "a Revolução de 64 foi para nós bem-vinda, desejada e saudada como um acontecimento que merecia o nosso aplauso". Leonel Brizola declarou por sua vez estar o jornal "atrelado aos interesses do capital monopolista". (DILLENBURG, 1997, p.6).

Breno Caldas também era um grande proprietário de terras, o que nos ajuda a entender as matérias referentes às mobilizações e a reforma agrária em seu jornal, Caldas era "detentor de uma área de 2.808,37 hectares no município de Viamão", além de "acionista da Arrozeira Brasileira S.A., que detinha vastas extensões de terra em Guaíba - 4.161 hectares - e Tapes 4.039, totalizando 8.200 hectares." (GASPAROTTO, 2016, p.32).

O Correio do Povo reconhece a necessidade da reforma agrária, que chama de "A Verdadeira Reforma Agrária” com seus fundamentos na educação, assistência técnica, crédito e inteirada com a realidade de cada estado, entretanto, opositora da real desapropriação, colocando pautas da classe rural em detrimento da transformação social, colocado pelo jornal como uma "Reforma Agrária Democrática".

Sobre o Movimento dos Agricultores Sem Terra, entre os anos de 1960 e 1962, não é visto citado em nenhuma notícia sobre os acampamentos, eventos reivindicatórios e conflitos por terras, o jornal se refere aos camponeses como "sem terras" e por vezes cita algumas associações - principalmente a Associação dos Agricultores Sem Terra de Camaquã que em janeiro de 1962 acamparam no Dique do Banhado do Colégio. Ademais, Milton Serres Rodrigues - Presidente do Master - emite uma nota a respeito da instalação de uma sede:

Comunicamos a todas as Associações e Uniões de Agricultores Sem Terra, como também a todos os que pretendam fundar Associações de Pequenos Agricultores, com ou sem terra, que este Movimento instalou sua sede estadual, local da futura Federação, à Rua Voluntários da Pátria, 984 - $1^{\circ}$ andar, onde já estamos trabalhando e prestando assistência e informações sobre a marcha da nossa luta pela Reforma Agrária. (Correio do Povo, 25 de março de 1962, p.48).

Já no ano de 1963, o movimento aparece superficialmente no jornal, veiculado em matérias que pouco ou nada relacionam os acampamentos à luta do campesinato pela reforma agrária. Superficialidade esta, que a certo modo, pode ser encarada como a tentativa retratar 
uma falsa desmobilização do movimento, ou ainda, uma maneira de caracterizar o campesinato a partir de uma suposta inércia desmobilizadora.

Outro ponto que chama a atenção são as notas de opinião do jornalista Dámaso Rocha sobre o governo de Brizola relacionado com a desapropriação de Nonoai (onde aconteceu o acampamento na Fazenda Sarandi em janeiro de 1962) este coloca que a mise en scène refere-se à cautela do Governador Leonel Brizola frente ao movimento em Nonoai liderado pelo Prefeito, que também é primo de Brizola, sr. Jair de Moura Calixto - foi preparada para vincular, de forma insuspeita, o governador à linha política das Ligas Camponesas. Também comenta sobre as notícias de que as terras em Sarandi estariam abandonadas seriam enganosas. Na opinião de Dámaso, Brizola antes de deixar o governo, desejaria armar-se de títulos que o credenciassem a uma liderança popular, com que pretendia investir contra os "padrões tradicionais" da política brasileira. Complementa que a palavra "camponês" vem incorporada de um conteúdo político, visto que

onde mais frequentemente encontramos são nos escritos políticos que tratam do problema agrário e dos surtos revolucionários em que os trabalhadores do campo tem participação destacada. Incorporou-se o jargão socialista e comunista como a designar a classe explorada pelos latifundiários. Quando a luta de classe é levada para o campo, a palavra "camponês" está sempre ao latifúndio. É com esta característica que ela participa da agitação social das esquerdas extremadas aqui no Brasil. (Correio do Povo, 27 de abril de 1962, p.4).

Afirma que em alguns países se tem dado importância ao homem do campo na luta de classes e na revolução social de outros povos, são países onde existe excesso de população e escassez de terras - destaca que não é o caso do Brasil. Damáso Rocha atuou no combate ao Partido Comunista Brasileiro (PCB) e observa que em muitos países assim foi como começou a revolução social, acabando, em alguns, por implantar o comunismo como forma de governo.

\begin{abstract}
As Ligas no Nordeste são muito mais políticas do que agrárias. O que tudo isso se conclui, sem muito esforço, é que de reforma agrária o que apenas interessa ao governador é o seu proveito político. E mais do que isto, o instrumento de agitação que ela comporta. $\mathrm{O}$ seu desmedido apetite com que dela procura tirar a maior vantagem possível, nos últimos meses de mandato, explica tudo aquilo que para muitos poderá parecer ainda confuso e incompreensível [...] (Correio do Povo, 11 de maio de 1962, p.4).
\end{abstract}

No entanto, percebemos a importância da discussão sobre o efeito político e social gerado com as intenções midiáticas, uma vez que a delimitação da memória e ressignificação altera o nosso presente. Essa invisibilidade do movimento nos textos veiculados pelo Correio do Povo deve ser pensado e analisado para além do que esta em suas páginas. 


\section{Conclusões}

O propósito do presente texto foi apresentar um debate acerca deste formato de imprensa frente à representatividade efetiva do Master. Por meio de tal proposta, é possível observar a implicação direta da invisibilidade do campesinato e do Master. Invisibilidade e silenciamento ostensivo visto que coloca uma das referências para aquele meio sob uma superficialidade desmobilizadora e estratégia política.

Em suma, não devemos entender o Movimento dos Agricultores Sem Terra na inércia dos acontecimentos oficiais, conhecemos sua atuação, ainda que não proferida no jornal, de importante luta e resistência. $\mathrm{O}$ que se pretende fazer nesta análise das fontes midiáticas é o que Douglas Kellner denomina em sua obra como "crítica diagnóstica", ele se propõe a analisar a cultura que envolve a mídia, analisando a recepção na sociedade - a construção de identidades - sobre os questionamentos dos discursos opressores e progressistas preferidos pela mídia. Dentro desta óptica, é preciso estabelecer uma relação entre a fonte estudada e a cultura que a cercava.

De qualquer modo, os efeitos da cultura da mídia são muito complexos e mediados, exigindo estudos da origem e da produção e dos modos como os indivíduos os usam para produzir significados, discursos e identidades. (KELLNER, 2001, p.142).

De forma essa, que mesmo na tentativa de se encontrar fontes alternativas, não deve se perder de vista a potencialidade dos jornais como suporte ideológico. No caso do jornal analisado, percebeu-se marcante sua elaboração, ao lado de outras organizações ruralistas do estado, a tentativa de colocar a reforma agrária no marco do "problema viável", em que a efetivação de desapropriações se encontram em último plano.

Com o golpe de 1964, o movimento foi violentamente reprimido, "implicando em profundo retrocesso na organização e mobilização do campesinato, de alguma forma o espaço conquistado por esse setor foi mantido [...]" (ECKERT, 1984, p.19). Visamos contribuir para a divulgação de estudos que tratem da história e da memória dos/as camponeses/as como sujeitos de direitos, estimulando a produção e discussão em todos os âmbitos.

\section{Referências}

BURKE, Peter. Testemunha ocular. História e imagem: EDUSC, 2004.

CANDAU, Joël. Memória e Identidade. São Paulo: Contexto, 2011.

CAPELATO, Maria Helena. Imprensa e História do Brasil. São Paulo: Contexto, 1988. 
DE TOLEDO, Caio Navarro. 1964: O golpe contra as reformas e a democracia. Revista Brasileira de História, São Paulo, v. 24, nº 47, p.13-28 - 2004

DILLENBURG, Sergio Roberto. História e Memória do Correio do Povo. Passo Fundo: EdUPF, 197.

ECKERT, Córdula. Movimento dos Agricultores sem Terra no Rio Grande do Sul (19601964). 1984. Tese (Doutorado) - Programa de Pós-Graduação em Ciências de Desenvolvimento Agrícola. Universidade Federal Rural do Rio de Janeiro.

ELMIR. Claudio Pereira. As armadilhas do jornal: algumas considerações metodológicas de seu uso para a pesquisa. Cadernos de Estudos do PPG em História (UFRGS), Porto Alegre, UFRGS, v.13, 1995.

GASPAROTTO, Alessandra. 'Companheiros Ruralistas!' Mobilização patronal e atuação política da Federação das Associações Rurais do Rio Grande do Sul (1959-1964). 2016.

Tese (Doutorado) - Programa de Pós-Graduação em História da Universidade Federal do Rio Grande do Sul.

KELLNER, Douglas. A cultura da mídia - estudos culturais: identidade e política entre o moderno e o pós -moderno, Bauru, SP, EDUSC, 2001.

LUCA, Tania Regina de. História dos, nos e por meio dos Periódicos. In.: PINSKY, Carla B. (Org.). Fontes Históricas. São Paulo: Contexto, 2006.

SAUER, Sérgio; SARAIVA, Regina C.F.; MEDEIROS, L.S.; VIANA, G; PORTO, C.A. (coords.). Relatório final: Violações de direitos no campo - 1946 a 198. Relatório da Comissão Camponesa da Verdade (CCV), Brasília, Senado Federal, 2014 (Relatório de pesquisa) - prelo e disponível em http://www.contag.org.br/arquivos/portal/file/site/Relatorio\%20Final\%20Comissao\%20Camp onesa\%20da\%20Verdade\%2009dez2014.pdf. 